\title{
Performance Evaluation of a Hybrid Thermal- Photovoltaic Panel
}

\author{
C. Moscatiello, Student Member, IEEE, C. Boccaletti, Senior Member, IEEE, A. Neto Alcaso, C. A. \\ Figueiredo Ramos, and A. J. Marques Cardoso, Senior Member, IEEE
}

\begin{abstract}
A theoretical and experimental analysis of a thermal-photovoltaic panel, whose purpose is to produce both electrical and thermal energy, has been performed. In order to achieve the main objective, the different components that constitute the thermal-photovoltaic panel have been studied and a simulation model of the thermal-photovoltaic panel has been developed. Furthermore, a prototype of the whole system, consisting of a commercial panel, the thermal and electrical circuits and an innovative wireless remote data acquisition system has been setup. The latter, based on an open-source electronic platform, has the necessary accuracy, and remote data capture and flexibility features. The model has been carefully calibrated and the simulated results, based on the solar irradiance, the ambient temperature and the wind speed, have been compared with experimental data. The results are analyzed and discussed in the paper. Such a validated model can be used to establish if and when it is more convenient to use a hybrid structure rather than two separate devices (PV only and thermal collector only).
\end{abstract}

Index Terms - Hybrid thermal-photovoltaic panel, photovoltaic panel, solar collector, remote monitoring.

\section{INTRODUCTION}

$\mathrm{T}$ HE functions of Photovoltaic Panels (PV) and thermal collectors can be integrated in a single device: the Photovoltaic-Thermal panel, or PV-T. With PV-Ts, the sunlight is converted into electricity and heat simultaneously. During the last 20 years the research into PV-T techniques and concepts has been widespread, but rather scattered. This reflects the number of possible PV-T concepts and the relevant research and development problems, deriving from the general goal to optimize both the electrical and the thermal efficiency of a device simultaneously. The aspects that can be optimized

C. Moscatiello and C. Boccaletti are with CISE - Electromechatronic Systems Research Centre, Covilhã, Portugal, and with the Dept. of Astronautics, Electrical and Energetic Engineering, Sapienza University of Rome, Italy (e-mail:_cristina.moscatiello@uniroma1.it, chiara.boccaletti@uniroma1.it).

A. Neto Alcaso and C. A. Figueiredo Ramos are with CISE Electromechatronic Systems Research Centre, Covilhã, Portugal, and with Polytechnic of Guarda, Guarda, Portugal (email: aderitona@ipg.pt, framos@ipg.pt).

A. J. Marques Cardoso is with CISE - Electromechatronic Systems Research Centre, Covilhã, Portugal, and with the University of Beira Interior, Dept. of Electromechanical Engineering, Portugal (e-mail: ajmcardoso@ieee.org). are, among others, the spectral characteristics of the PV cell, its solar absorption and the internal heat transfer between cells and heat-collecting system.

Another important level of optimization is relevant to the PV-T device geometry and the integration into a system. The electricity and heat demand and the temperature level of the latter determine the choice of a certain system set-up. With an optimal design, PV-T systems can supply buildings with $100 \%$ renewable electricity and heat in a more cost-effective manner than separate PV and solar thermal systems and thus contribute to the long-term international targets on implementation of renewable energy in the built environment [1].

Several types of PV-Ts exist, and they can be divided according to: heat transfer fluid (air, water or another refrigerant fluid), type of silicon that is used for the photovoltaic module; manner in which they receive the solar radiation (concentrated or flat plate solar collectors); mode of circulation of the fluid (natural or forced); location (integrated in the building, on the roof, or on the floor); presence of a glass cover or not. According to the first criterion there are PV-T air collectors, PV-T water collectors and PV-T liquid collectors. The fluid can flow in tubes below the absorber like in a traditional solar collector (sheet and tube); in a channel realized between the cover glass and the PV module; above the PV module (free flow); in two channels realized between the glass cover and the PV and the absorber and the insulator, respectively; below the PV module; in channels situated below the absorber.

The PV-T liquid collector is the most innovative and recent one. The basic liquid-cooled design uses conductive-metal piping or plates attached to the back of a PV module. The heat from the PV cells is driven through the metal and absorbed by the working fluid. It is possible to realize closed-loop or openloop systems: in closed-loop systems the heat is transferred to a heat exchanger, where it flows to the load; in open-loop systems, the heat is transferred before the fluid returns to the PV cells [2].

The solar air heating and water heating represent $45 \%$ and $39 \%$ of solar thermal technologies, respectively; the solar cooling constitutes $7 \%$, the industrial heating $6 \%$, the drying $3 \%$, and the pool heating $0.2 \%$. Mainly in the residential sector, the PV-T can be combined with a heat pump to serve multi-family buildings, with a limited occupancy of the available roof area [3].

In this work, the thermal and electrical performance of a PV$\mathrm{T}$ water collector are evaluated. 
With respect to a single PV module, in such a system the produced thermal energy that otherwise would be dispersed in the environment is stored and used, and at the same time the photovoltaic module is cooled, increasing its efficiency, which decays with increasing temperature. In the same ambient conditions, and considering the same surface area, the PV-T thermal efficiency is lower than that of the solar collector only (mainly because of the radiation absorbed by the PV layer), but the total efficiency per unit area of a PV-T panel is higher than the sum of the efficiencies of separate PV panels and solar thermal collectors, of which the occupied area would be about $40 \%$ larger for the same output. This is an advantage when the space availability is limited and when one has to pay attention to the visual impact. Indeed, the PV-T panels look better than separated PV modules and solar thermal collectors and this is important, for instance, when there are historical or natural constraints.

\section{THE PV-T SOlAR SYSTEM}

In Figure 1 the dimensions and layers of the considered PV$\mathrm{T}$ are depicted. Starting from the surface, the layers are: PV module, copper absorber, insulation, Styrofoam ${ }^{\mathrm{TM}}$, and backsheet. Table I reports some geometrical data. The panel is commercially available and has a nominal power of $200 \mathrm{~W}$.

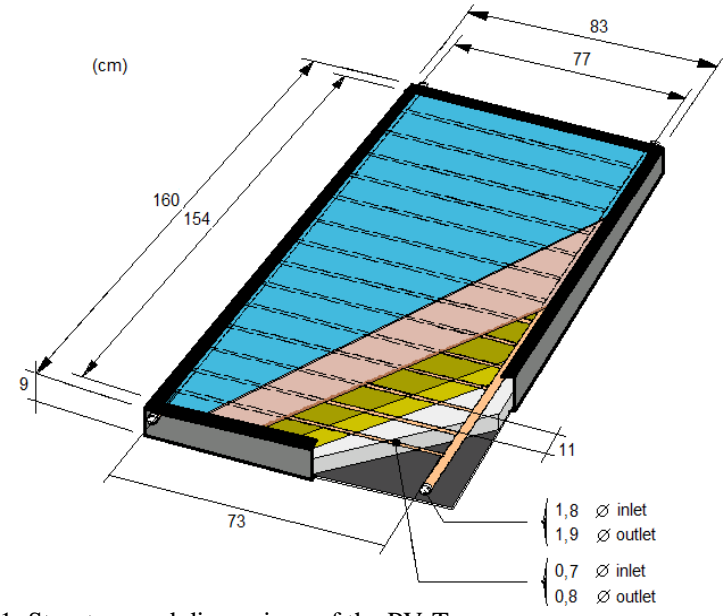

Fig. 1 Structure and dimensions of the PV-T.
TABLE I

PV-T MODULE DIMENSIONS

\begin{tabular}{lc}
\hline \hline Number of cells & $6 \times 12=72$ \\
Area of the cells & $1.52 \times 0.76=1.16 \mathrm{~m}^{2}$ \\
Number of collectors & 2 \\
Number of exchange tubes & 14 \\
\hline \hline
\end{tabular}

Figure 2 shows the operating principle of the PV-T. The cold water that comes from the grid and the tank appears in dark blue. It enters the main collector, where it is distributed in the 14 pipes at a pressure of about 1 bar. The red arrows represent the path of the hot water coming from the pipes where it received heat from the cells, lowering their temperature. For the sake of clarity, only the main devices that guarantee the proper operation of the PV-T appear in the scheme.

\section{MAthematical Model}

In the literature there are many theoretical and experimental works on PV-T collectors to evaluate the energy yield of systems with various configurations [4-8], and a review is also presented in [9]. Numerical/mathematical models, with variable levels of complexity (1D, 2D or 3D), are analyzed in [10]. Other studies regarding numerical models that can represent the behavior of the PV-T panel are available in the literature. In [11] a PV-T system has been analyzed using a one-dimensional thermal model based on energy transfer phenomena in the various PV-T components. In [12] a simulation performed with the TRNSYS software program and considering a typical meteorological year is presented.

In this paper, the mathematical model for the PV-T was developed merging the widely used one-dimensional HottelWhillier model [13-14] and a one-diode model [15-16] to simulate the thermal effects and the PV electrical power, respectively [17]. The model has been implemented in the Matlab/Simulink software environment and validated evaluating the PV-T performance of a panel commercially available equipped with a remote-access acquisition system to provide real-time data monitoring.

Literature values were taken as starting values for the model parameters and then fine-tuned in order to perform an accurate calibration of the model for the PV-T in question.
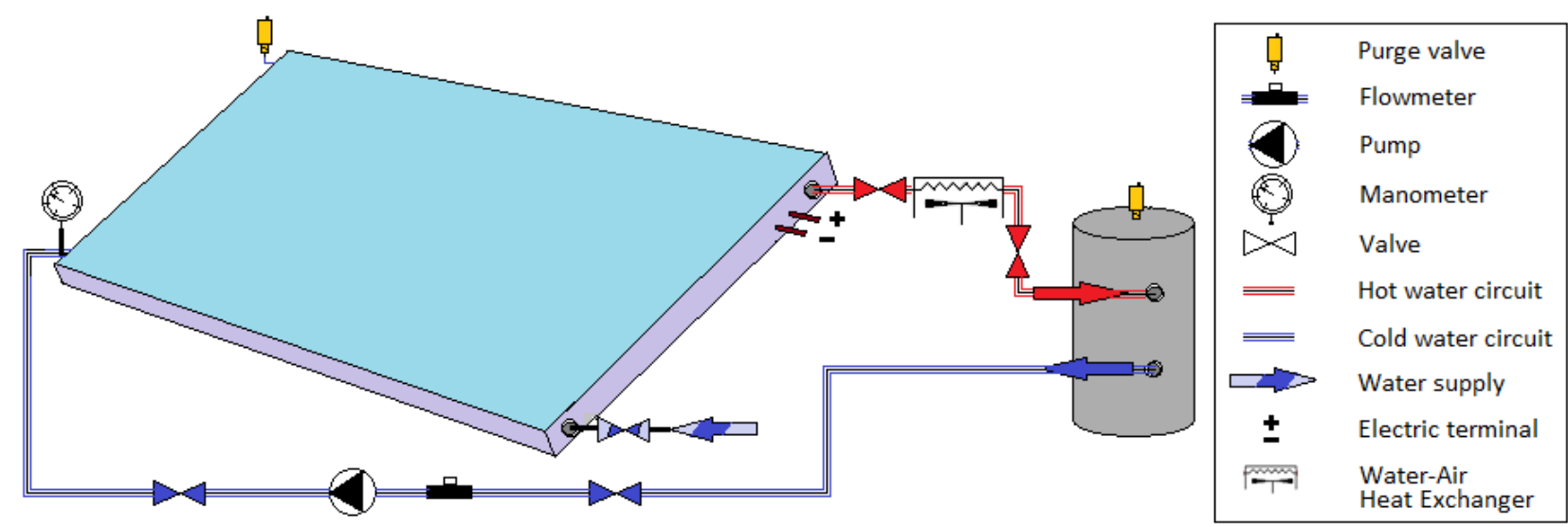

Fig. 2 Simplified scheme of PV-T operation. 


\section{A. Electrical Model}

For the electrical model, the basic equation derived from the theory of semiconductors, describing the I-V characteristic of the ideal PV, has been used

$$
\mathrm{I}=\mathrm{I}_{\mathrm{pv} \text {, cell }}-\mathrm{I}_{0, \text { cell }}\left[\mathrm{e}^{\mathrm{qV} / \mathrm{kKT}}-1\right]
$$

where $I_{p v, \text { cell }}$ is the current generated by the incident light, $I_{0, \text { cell }}$ is the reverse saturation current of the diode, $q$ is the electron charge, $K$ is the Boltzmann constant, $T$ is the temperature of the $\mathrm{p}-\mathrm{n}$ junction and $a$ is the diode ideality constant [15-16].

However, the previous equation is not able to represent the I$\mathrm{V}$ characteristic of an array enough accurately. Therefore, it is necessary to introduce additional parameters which can improve basic equation (1)

$$
\mathrm{I}=\mathrm{I}_{\mathrm{pv}}-\mathrm{I}_{0}\left[\exp \left(\frac{\mathrm{V}+\mathrm{R}_{\mathrm{S}} \mathrm{I}}{\mathrm{V}_{\mathrm{t}} \mathrm{a}}\right)-1\right]-\frac{\mathrm{VR}_{\mathrm{S}} \mathrm{I}}{\mathrm{R}_{\mathrm{P}}}
$$

where $I_{p v}$ is the photovoltaic current of array, $I_{0}$ the saturation current, $V_{t}=N_{s} K T / q$ is the thermal voltage of the array with $N_{S}$ cells connected in series. Terms $R_{S}$ and $R_{P}$ that appear in equation (2) are the equivalent series resistance of the array and the equivalent parallel resistance, respectively. $R_{S}$ is the sum of several structural resistances of the device. In Figure 3 the characteristic I-V curve of a practical PV is shown, obtained from equation (2), with its three remarkable points that are: short circuit $\left(0, I_{s c}\right)$, maximum power point $\left(V_{m p}, I_{m p}\right)$, and open circuit $\left(V_{o c}, 0\right)$.

The parameters supplied by the manufacturers of the PV arrays are not many, and sometimes not enough to allow the adjustment of the models. In fact, it is possible to find in the datasheets only the nominal short-circuit current $\left(I_{s c, n}\right)$, the nominal open circuit voltage $\left(V_{o c, n}\right)$, the current $\left(I_{m p}\right)$ and the voltage $\left(V_{m p}\right)$ at the maximum power point, the open-circuit voltage/temperature coefficient $\left(K_{V}\right)$, the short-circuit current/temperature coefficient $\left(K_{l}\right)$, and the maximum experimental peak output power $\left(P_{M A X, e}\right)$. Some of the parameters that are not usually shown on the datasheets are, for example, the saturation current of the diode, the lightgenerated or PV current, the series and parallel resistance, etc.. Some manufacturers provide I-V curves for several radiation and temperature conditions, which facilitate the adjustment and validation of the mathematical equations.

As it can be seen in Figure 3, the practical PV device may function as both a voltage and a current generator. According to the working point, $R_{S}$ is most affected when it operates as a voltage generator while $R_{p}$ is greater when it has the function of current generator. Thus, it can be observed that the I-V characteristic of a PV device depends not only on solar radiation and temperature, but also on the internal characteristics of the device, that is, $R_{S}$ and $R_{P}$. Instead, if we neglect the series and parallel resistances it is difficult to determine the light-generated current $\left(I_{P V}\right)$, because the datasheets show only the nominal short-circuit current $\left(I_{S C, n}\right)$, which is the maximum current available at the terminals of the practical device. However, in practical devices the series resistance is low and the parallel resistance is comparatively high, therefore one can assume $I_{S C, n} \approx I_{P V}$ in the modeling of PV devices.
The light-generated current of the PV cell depends linearly on the solar radiation and is also influenced by the temperature, according to the following equation:

$$
I_{P V}=\left(I_{P V, n}+K_{l} \Delta T\right) \frac{G_{a}}{G_{n}}
$$

where $I_{P V, n}$ is the PV current at the nominal condition; $\Delta T=T_{c^{-}}$ $T_{n}\left(T_{c}\right.$ and $T_{n}$ being the actual and nominal temperatures); $G_{a}$ is the radiation on the device surface; $G_{n}=1000 \mathrm{~W} / \mathrm{m}^{2}$ is the nominal radiation. The diode saturation current $I_{0}$ and its dependence on the temperature may be expressed by

$$
I_{0}=I_{0, n}\left(\frac{T_{n}}{T_{C}}\right)^{2} \exp \left[\frac{q E_{g}}{a k}\left(\frac{1}{T_{n}}-\frac{1}{T_{c}}\right)\right]
$$

where $E_{g}=1.12 \mathrm{eV}$ is the bandgap energy of the semiconductor for the polycrystalline $\mathrm{Si}$ at $25^{\circ} \mathrm{C}$, and $I_{0, n}$ is the nominal saturation current. The value of the latter is determined by the following equation

$$
I_{0, n}=\frac{I_{S C, n}}{\exp \left(\frac{V_{o c, n}}{a V_{t, n}}-1\right)}
$$

where $V_{t, n}$ is the thermal voltage of $N_{S}$ series-connected cells at nominal temperature $T_{n}$.

The saturation current $I_{0}$ of the PV cells that compose the device depends on the saturation current density of the semiconductor and on the effective area of the cells. Current density $J_{0}$ depends on the intrinsic characteristics of the PV cell, which in turn depend on several physical parameters such as the coefficient of diffusion of electrons in the semiconductor, the lifetime of minority carriers, the intrinsic carrier density, etc..

As regards the value of diode constant $a$, it could be estimated with precision. However, the value of this constant is usually $1 \leq a \leq 1.5$ and its choice depends on the parameters of the I-V model. Also, values of $a$ can be obtained from an empirical analysis. The value of this constant is not to be underestimated because it affects the curvature of the I-V curves and slight variations can improve the model accuracy.

Finally, series resistance $R_{S}$ and parallel resistance $R_{p}$ have to be estimated. In the literature there are several methods to determine them mathematically. According to some authors, it is possible to calculate the two resistors separately. However, this method is not very precise and does not allow to find a good I-V curve. Instead, the method used in this paper is based on the fact that there is only a couple of $R_{S}$ and $R_{p}$ for which $P_{\max , m}=P_{\max , e}=V_{m p} I_{m p}$ at point $\left(V_{m p}, I_{m p}\right)$ of I-V curve; in other words, the maximum power calculated by the $\mathrm{I}-\mathrm{V}$ model $\left(P_{\max , m}\right)$ must be equal to the maximum power from the datasheet $\left(P_{\max , e}\right)$ at the MPP.

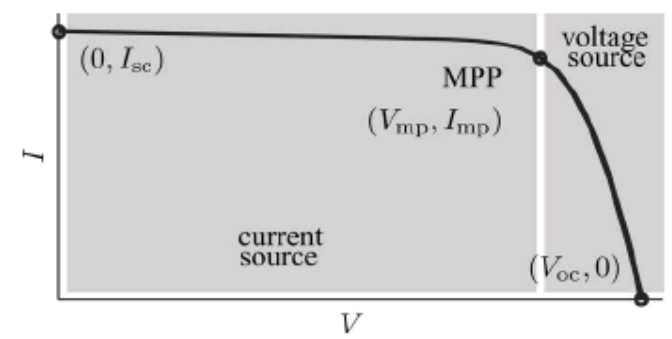

Fig. 3 Characteristic I-V curve of a practical PV. 
Therefore, it is possible to derive the relationship between $R_{S}$ and $R_{P}$ through $P_{\max , m}=P_{\max , e}$ and solve the resulting equation for $R_{P}$, as follows

$$
\begin{gathered}
P_{\text {max }, m}=V_{m p}\left\{I_{p v}-I_{0}\left[\exp \left(\frac{q}{k T} \frac{V_{m p}+R_{S} I_{m p}}{a N_{s}}\right)-1\right]-\frac{V_{m p}+R_{S} I_{m p}}{R_{p}}\right\}=P_{\max , e} \\
R_{p}=\frac{V_{m p}\left(V_{m p}+R_{S} I_{m p}\right)}{\left[V_{m p} I_{P V}-V_{m p} I_{0} \exp \left(\frac{q}{k T} \frac{V_{m p}+R_{S} I_{m p}}{a N_{S}}\right)+V_{m p} I_{0}-P_{\max , e}\right]}
\end{gathered}
$$

The above equations have been implemented in the Matlab/Simulink software environment.

\section{B. Thermal Model}

Regarding the thermal part, a 1D model was used to reduce the calculation time. The proposed 1D model is a HottelWhillier model [13-14] in which the thermal power and efficiency, respectively, are given by

$$
\begin{aligned}
& P_{t h}=A_{P V} F_{R}\left(\left(\tau_{a}-\tau \eta_{e l}\right) G_{a}-U_{\text {loss }}\left(T_{i n}-T_{a}\right)\right) \\
& \eta_{t h}=F_{R}\left(\tau_{a}-\tau \eta_{e l}\right)+F_{R} U_{\text {loss }}\left(T_{i n}-T_{a}\right) / G_{a}
\end{aligned}
$$

where $F_{R}$ represents the heat removal factor:

$$
F_{R}=\frac{\dot{m} c}{A_{P V} U_{l o s s}}\left(1-\exp \left[A_{P V} U_{l o s s} F^{\prime} / \dot{m} c\right]\right)
$$

and

$$
F^{\prime}=\left\{\frac{1}{F_{t}}+\frac{U_{\text {loss }}}{h_{\text {ca }}}+\frac{U_{\text {loss }} W}{\pi D h_{\text {tube }}}\right\}^{-1}
$$

All the equations used here are the same equations that describe a conventional thermal collector, apart from the additional term $U_{\text {loss }} / h_{c a}$ that appears in equation (11), representing the heat resistance between cells and absorber. In equations (8) and (9) term $\tau \eta_{e l}$ accounts for the solar radiation absorbed by the PV cells, which obviously is not any more available to be converted in thermal energy.

Factor $F_{t}$ depends on the diameter of the tubes $D$, their distance $W$ and the heat exchange coefficient $h$.

$$
\begin{gathered}
F_{t}=\left(1-\frac{D}{W}\right) F+\frac{D}{W} \\
F=\frac{\tanh \left[\frac{m(W-D)}{2}\right]}{m(W-D) / 2}
\end{gathered}
$$

In the last equation $m$ can be calculated as

$$
m=\left(\frac{h_{\text {loss }}}{K_{a b s} \delta_{a b s}+K_{\text {lam }} \delta_{\text {lam }}}\right)
$$

where $K_{a b s}$ and $K_{\text {lam }}$ are the absorber and laminate thermal conductivity and $\delta_{\text {abs }}$ and $\delta_{\text {lam }}$ are the absorber and laminate thickness. Furthermore, to calculate the thermal yield, the cover heat exchange coefficient $U_{\text {loss }}$ and the heat transfer coefficient from the tube to the water $h_{\text {tube }}$ are also needed

$$
\begin{aligned}
U_{\text {loss }} & =\left[\frac{N}{\frac{C}{T_{C}}\left(\frac{T_{C}-T_{a}}{N+f}\right)^{e}}+\frac{1}{h_{\text {wind }}}\right]^{-1}+ \\
& +\frac{\sigma\left(T_{C}{ }^{2}+T_{a}^{2}\right)\left(T_{C}+T_{a}\right)}{\left(\varepsilon_{\text {lam }}+0.00591 N h_{\text {wind }}\right)^{-1}+\frac{2 N+f-1+0.133 \varepsilon_{\text {lam }}}{\varepsilon_{\text {glass }}}-N}
\end{aligned}
$$

where:

$N=$ number of glass covers;

$f=\left(-1+0.089 \mathrm{~h}_{\text {wind }}-0.1166 \mathrm{~h}_{\text {wind }} \varepsilon_{\text {lam }}\right)(1+0.07866 \mathrm{~N})$;

$C=520\left(1-0.000051 \phi^{2}\right)$ for $0^{\circ}<\phi<70^{\circ}$;

$e=0.430\left(1-100 / \mathrm{T}_{\mathrm{C}}\right)$;

$h_{\text {wind }}=5.7+3.8 S_{\text {wind }}$, is the wind heat transfer coefficient $\left(\mathrm{W} / \mathrm{m}^{2} \mathrm{~K}\right), S_{\text {wind }}$ is the wind speed, $\sigma$ is the Stefan-Boltzmann constant and $\varepsilon_{\text {glass }}$ and $\varepsilon_{\text {lam }}$ are glass and laminate emissivity coefficients, respectively. In particular, $h_{\text {wind }}$ is one of the most sensitive parameters and required a careful calibration.

It is possible to calculate the heat transfer coefficient from the tube to the water as follows

$$
h_{\text {tube }}=\frac{\pi K_{W} N U_{\text {tube }}}{W}
$$

The heat transfer coefficient from cells to absorber $h_{c a}$ is estimated in $45 \mathrm{~W} / \mathrm{m}^{2} \mathrm{~K}$. Also for the simulation of the thermal part the Matlab/Simulink software tool was used.

Finally, the electrical and the thermal model have been integrated in a single model, of which the coupling term is the mean temperature of the PV-T layers.

\section{Simulation Results}

The complete simulation model was used to perform some calculations to analyze the panel performance. The thermal power produced by the PV-T, operating as a thermal collector only, was compared with that of the collector integrated with the PV panel (combi). As shown in Figure 4, the thermal power is higher for the collector only, than for the combined (PV-T) system. It has a peak of about $535 \mathrm{~W}$ at 01:43 pm.

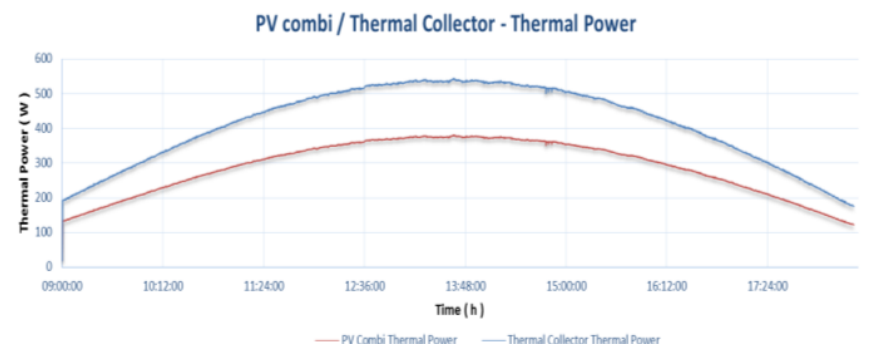

Fig. 4 Thermal power for the two cases of PV-T operating as a hybrid device (combi, red) and as thermal collector only (blue).

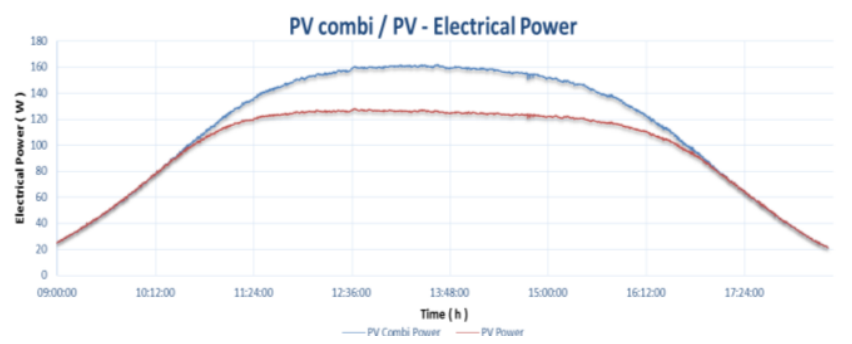

Fig. 5 Electrical power for the two cases of PV-T operating as a hybrid device (combi, blue) and as PV only (red).

This result was obviously expected, since part of the incident radiation is absorbed by the PV panel before reaching the collector absorbing surface. Unlike the thermal power, the electrical output power is higher in the case of combined system, as shown in Figure 5. It has a peak of $162 \mathrm{~W}$ at 01:37 $\mathrm{pm}$. This is due to the positive effect of the temperature 
reduction, which is a consequence of the heat removal, on the PV efficiency [18-20]. Actually, it is possible to observe that the difference between the two curves of the electrical power is more evident in the central hours of the day, when the "cooling effect" of the combined panel is more intense, while it is negligible during the hours of smaller radiation.

\section{EXPERIMENTAL SETUP}

The simulation model was experimentally validated at the Guarda International Research Station on Renewable Energies (http://www.cise.ubi.pt/index.php?op=res) in Portugal. The experimental setup, shown in Figure 6 (a) and (b), is constituted by a thermal-photovoltaic panel (PowerVolt by Solimpeks Solar $\mathrm{GmbH}$ ) with the characteristics shown in Table II; a pyranometer (KIPP and ZONEN, CMP3) for measuring the solar irradiance; temperature sensors (RTDs of PT100 type), a turbine flowmeter (Gems sensors, FT-110 Series) for measuring the water mass flow rate; a tank where the water is collected and several valves (Caleffi, 5024); a current transducer (LEM, HY 5..25-P); a combined transmitter (ThiesClima_Wind, 4.3329.00.510) for the measurement of wind velocity, wind direction and air temperature; a pump (Flojet, 4125 Series), to ensure the circulation of the water; a voltage transducer (LEM, LV 25-P); an electronic box with four boards, one for each type of measured variable. This innovative method of data collection has been used to perform measurements on the PV-T. It consists in connecting each board to Arduino Leonardo, a microcontroller board based on low-power microchip ATmega32ua. This microcontroller is able to supply the measured data to Arduino Yun. The latter has the same microcontroller board, dimensions, memory and connectors as Leonardo, and can send the data to a computer wirelessly [21]. This solution based on Arduino, an opensource electronic platform, represents a low-cost data acquisition system and has interesting features like the flexibility, the remote data capture capability, and an accuracy satisfactory enough to allow model validation. A similar type of solution has already been used on other devices for the energy production from renewable sources [22-23].

TABLE II

PV-T PANEL CHARACTERISTICS

\begin{tabular}{cc}
\hline \hline$P_{\max }[\mathrm{W}]$ & 200 \\
$I_{m p}[\mathrm{~A}]$ & 5.43 \\
$V_{m p}[\mathrm{~V}]$ & 36.8 \\
$I_{s c}[\mathrm{~A}]$ & 5.67 \\
$V_{o c}[\mathrm{~V}]$ & 46.43 \\
Dimensions $[\mathrm{mm}]$ & $1601 \times 828 \times 90$ \\
Weight $[\mathrm{kg}]$ & 24.4 \\
\hline \hline
\end{tabular}

\section{EXPERIMENTAL RESULTS}

Figures 7, 8 and 9 show the comparison between the measured values and those calculated by means of the simulation model. In particular, in Figure 8 the measured outflow temperature of the combined system and that calculated by simulation are compared. As it is evident from the graph, the error is very low, and the same happens in the case of output current and voltage (Figures 9 and 10).
Therefore, the model can be considered as a reliable tool to study the performance of PV-Ts having a structure similar to the one object of this work.
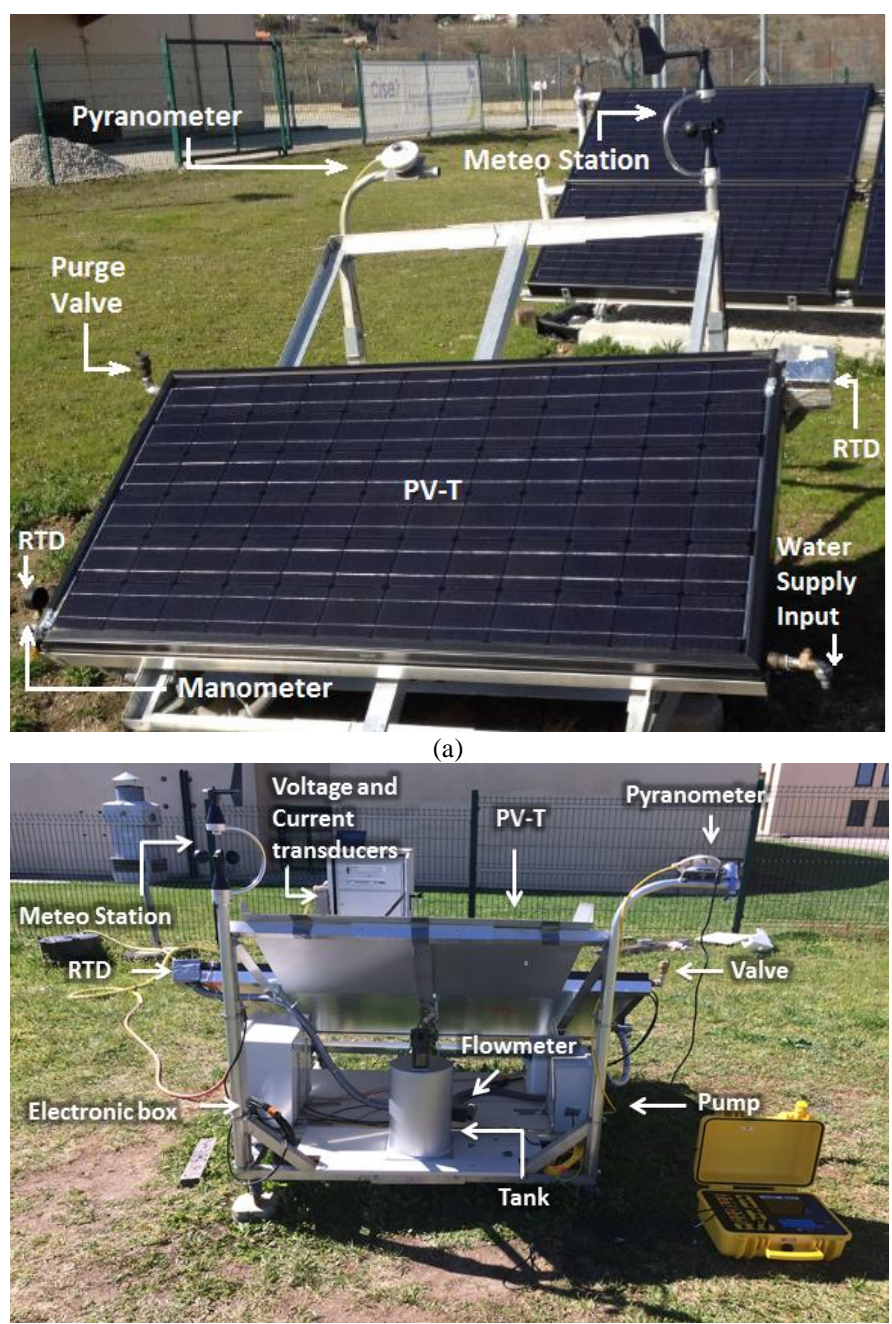

(b)

Fig. 6 Experimental setup: (a) front view; (b) rear view.

T out

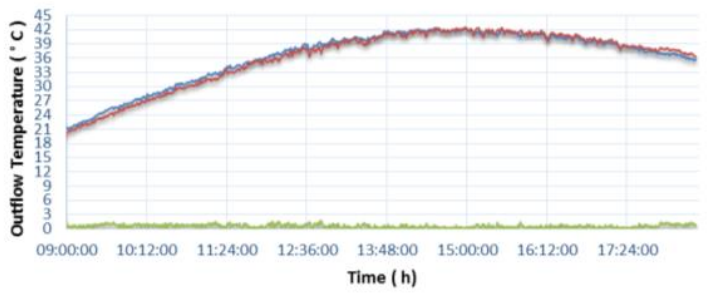

- Measured Tout Calculated Tout - Error

Fig. 7 Comparison between measured (blue) and calculated outflow temperature (red). The corresponding error is represented by the green curve. Current

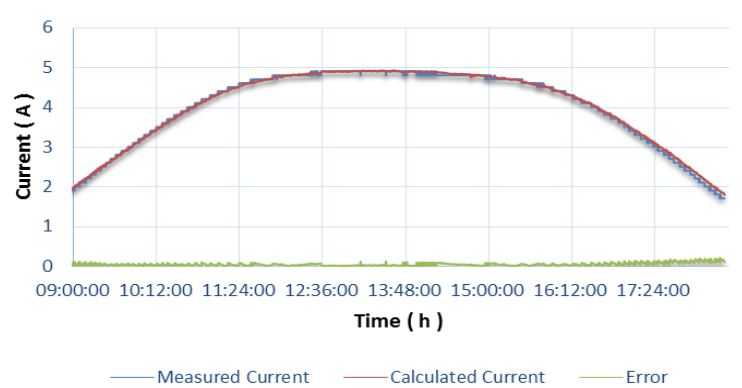


Fig. 8 Comparison between measured (blue) and calculated current (red).

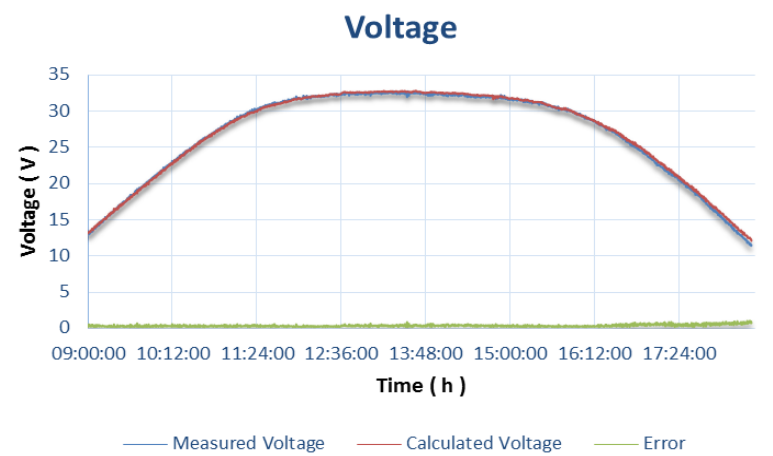

Fig. 9 Comparison between measured (blue) and calculated output voltage (red).

\section{Discussion AND CONCLUSIONS}

A hybrid thermal-photovoltaic panel has been modelled and the proposed simulation model has been accurately calibrated and validated with experimental data, showing a very good agreement. The developed model allows to evaluate the energy production in every condition through the use of local measured input data. The modularity of the model is also suitable for use with other devices in combined applications. Therefore, it can be concluded that the model provides an excellent tool to analyze the performance of PV-Ts.

To perform the experimental tests, a complete system has been installed at the Guarda International Research Station on Renewable Energies (CISE | GIRS-RES), and an innovative remote acquisition platform has been used to collect the necessary data from the sensors. Thanks to this system, the latter are available in real time via internet, therefore easily accessible from whatever place in the world where a connection is available.

In a PV-T panel two devices are combined in a single system, saving space and obtaining a better electrical performance. In fact, the electrical power and efficiency are higher when the PV is used in combination with the collector, because the latter contributes to lower the temperature of the cells. This performance improvement, however, comes at the expense of the thermal performance of the collector, since part of the incident energy is now absorbed by the PV panel with respect to a separated thermal collector with the same surface area. As a result, to obtain the same thermal output of a separate device, the PV-T surface area cannot be just halved, but can be reduced by about $40 \%$.

This kind of systems are suitable to both industrial and residential applications. As an example, it can be used in a sawmill [24] in which the PV-T system is an auxiliary preheater, while the main system consists of a traditional heater fed by sawmill wood residues like coarse, sawdust, bark and shavings, and a water-air heat exchanger provides hot air to the dry kiln for wood drying. While the heat is used to dry the lumber, the electricity is used to supply saws, fans, condensate pumps and air compressors.

As regards the residential sector, besides the generated electricity, the waste heat can be exploited for instance to heat domestic hot water [25-26]. In fact, a PV-T of about 3 to $5 \mathrm{~m}^{2}$ installed in a family house, of which the thermal circuit is based on the thermosyphon principle and is equipped with a water storage tank of 150 to 3001 , showed a good performance: an increase of $4 \%$ in electrical efficiency and an annual solar fraction of 0.7621 [27].

In conclusion, PV-T features are very interesting when there is a demand for both thermal and electrical energy and there is a commitment to the use of renewable energies, even in presence of strict space and/or visual impact constraints. Although the high initial cost, when there are no particular constraints limiting the use of separate devices (available space, visual impact), the economic feasibility of such plants should be evaluated case by case [28] and further technological and commercial development could guarantee higher revenues.

\section{ACKNOWLEDGEMENT}

The authors gratefully acknowledge the support of the Portuguese Foundation for Science and Technology under Project No. UID/EEA/004131/2013 and Project No. SFRH/BSAB/118741/2016.

\section{REFERENCES}

[1] W. G. J. Van Helden, R. J. C. Van Zolingen, H. A. Zondag, "PV thermal systems: PV panels supplying renewable electricity and heat," Prog Photovoltaics Res Appl, 12, 2004, pp. 415-426.

[2] A. Makki, S. Omer and H. Sabir--" Advancements in hybrid photovoltaic systems for enhanced solar cells performance," Renewable and Sustainable Energy Reviews, vol. 41, 2015, pp. 658-684.

[3] H. A. Zondag, W. G. J. Van Helden, M. Bakker, P. Affolter, W. Eisenmann, H. Fechner, M. Rommel, A. Schaap, H. Sörensen, Y. Tripanagnostopoulos, "PVT roadmap: a European guide for the development and market introduction of PVT technology," in 20th European Photovoltaic Solar Energy Conf., Barcelona, Spain, 2005.

[4] B. J. Huang, T. H. Lin, W. C. Hung and F. S. Sun, "Performance evaluation of solar photovoltaic/thermal systems," Solar Energy, vol. 70, 2001, pp 443-448.

[5] S. Kumar, G. N. Tiwari, "An experimental study of hybrid photovoltaic thermal (PV/T) - active solar still," Int J Energy Res 32, 2008, pp. 847858.

[6] H. Saitoh, Y. Hamada, H. Kubota, M. Nakamura, K. Ochifuji, S. Yokoyama et al., "Field experiments and analysis on a hybrid solar collector", Applied Thermal Engineering, 23, 2003, pp. 2089-2105.

[7] R. Santbergen, C. C. M. Rindt, H. A. Zondag, R. J. Ch. van Zolingen, "Detailed analysis of the energy yield of systems with covered sheetand-tube PVT collectors," Solar Energy, vol. 84, 2003, pp. 867-878.

[8] J. Bliss, "The Derivations of Several "Plate-Efficiency Factors" Useful in the Design of Flate-Plate Heat Collectors," Solar Energy, 3, 4, 1959, pp. 55-64.

[9] C. A. F. Ramos, A. J. M. Cardoso, A. N. Alcaso, "Hybrid photovoltaicthermal collectors: A review," Emerging Trends in Technological Innovation, vol. 314,2010 , pp 477-484.

[10] H. A. Zondag, D. W. De Vries, W. G. J. Van Helden, R. J. C. Van Zolingen and A. A. Van Steenhoven, "The thermal and electrical yield of a PV-thermal collector," Solar Energy, 72, 2002, pp. 113-128.

[11] C. A. F. Ramos, A. J. M. Cardoso and A. N. Alcaso, "Modeling and simulation of a hybrid photovoltaic/thermal collector," in Int. Renewable Energy Congress, vol. 1, 2011, pp 455-460.

[12] S. A. Kalogirou, "Use of TRNSYS for modeling and simulation of a hybrid PV-thermal solar system for Cyprus," Renewable Energy, 23, 2, 2001, pp. 247-260.

[13] H. Hottel, B. Woertz, "The performance of flat plate solar heat collector," Trans. ASME, 64, 1942, pp. 91-104.

[14] H. Hottel, A. Whillier, "Evaluation of flat-plate solar collector performance," in Trans. of the Conf. on the Use of Solar Energy Thermal Processes, Tucson, AZ, 1955, pp. 74-104.

[15] B. Alsayid, J. Jallad, "Modeling and simulation of photovoltaic cells/modules/arrays", Int. Journal of Research and Reviews in Computer Science, 2.6, 2011, pp. 1327-1331. 
[16] M. G. Villalva, J. R. Gazoli and E. R. Filho, "Comprehensive approach to modeling and simulation of photovoltaic arrays," IEEE Trans. on Power Electronics, vol. 24, No. 5, 2009, pp 1198-1208.

[17] C. Moscatiello, C. Boccaletti, A. N. Alcaso, C. A. F. Ramos, A. J. M. Cardoso, "Performance evaluation of a hybrid thermal-photovoltaic panel," in IEEE Energy Conversion Congress and Exposition, Milwaukee, WI, USA, 2016.

[18] N. Aste, F. Leonforte, C. Del Pero, "Design, modeling and performance monitoring of a photovoltaic-thermal (PVT) water collector," Solar Energy, 112, 2015, pp. 85-99.

[19] D. Dirnberger, B. Muller, C. Reise, "On the uncertainty of energetic impact on the yield of diff erent PV technologies due to varying spectral irradiance," Solar Energy, 111, 2015, pp. 82-96.

[20] I. Guarracino, A. Mellor, N. J. Ekins-Daukes, C. N. Markides, "Dynamic coupled thermal-and-electrical modelling of sheet-and-tube hybrid photovoltaic/thermal (PVT) collectors," Appl. Th. Engng., 101, 2016, pp. 778-795.

[21] L. M. G. Saraiva, A. N. Alcaso, P. A. A. Vieira, C. A. F. Ramos, A. J. M. Cardoso, "Development of a cloud-based system for remote monitoring of a PVT panel," Open Engineering, vol. 6, Issue 1, pp. 291297, October 2016.

[22] M. Fuentes, M. Vivar, J. M. Burgos, J. Aguilera, J. A. Vacas, "Design of an accurate, low-cost autonomous data logger for PV system monitoring using Arduino that complies with IEC standards," Solar Energy Materials and Solar Cells, 130, 2014, pp. 529-543.

[23] A. J. Caldéron, I. Gonzalez, M. Calderon, F. Segura, J. M. Andujar, “A new, scalable and low cost multi-channel monitoring system for polymer electrolyte fuel cells," Sensors, 16, 2016, pp. 348-366.

[24] C. Boccaletti, M. Macilletti, "Electrical storage systems in cogeneration plants based on the solar energy source," in Int. Conf. on Clean Electrical Power, Ischia, Italy, 2011.

[25] H. Pierrick, C. Menezo, L. Gaillard, P. Dupeyrat, "Dynamic numerical model of a high efficiency PV-T collector integrated into a domestic hot water system," Solar Energy, 111, 2014, pp. 68-81.

[26] M. D. Bazilian, D. Prasad, "A holistic approach to voltaic/thermal/daylight (PV/T/L) cogeneration," in Eurosun 2000, Copenhagen, Denmark, 2000.

[27] M. Shihabudheen, and P. Arun, "Performance evaluation of a hybrid photovoltaic-thermal water heating system”, Int. J. Green Energy, 2013, pp. 969-986.

[28] K-K. Tse, T-T. Chow, Y. Su, "Performance evaluation and economic analysis of a full scalewater-based photovoltaic/thermal (PV/T) system in an office building," Energy and Buildings, 122, 2016, pp. 42-52.

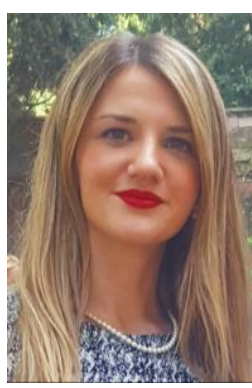

Cristina Moscatiello (StM'14) was born in Rome, Italy in 1990. She got her Bachelor Degree and M.S. Degree in Energetic Engineering at Sapienza University of Rome, where she is currently a Ph.D. Student. She is member of IAS (Italian section) since 2014 and IEEE IAS SBC Vice Chair since 2016.

Her research interests are focused on Renewable Energies and Home and Building Automation.

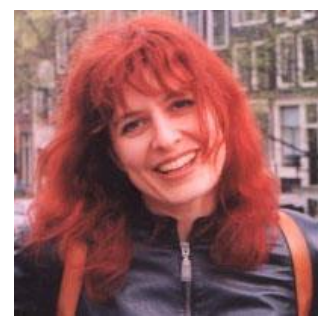

C. Boccaletti (M'04, SM'14) was born in Bologna (Italy) in 1967. She received the M.S. degree in Mechanical Engineering and the Ph.D. degree in Energetics from Sapienza University of Rome (Italy) in 1991 and 1995, respectively. In 1998 she was the recipient of the National Award "Energy and Environment" for her PhD thesis. She has carried out an independent professional activity in several industrial and research fields for 7 years. In 1998 she was engaged as assistant professor at the Roma Tre University (Italy), and in 2002 moved to the Sapienza University of
Rome. She also collaborates with CISE - Electromechatronic Systems Research Centre (http://cise.ubi.pt). Prof. Boccaletti has been Member-at-large of IAS Executive Board in 2016 and IAS Treasurer 2017-2018. She has been a member of ASME until 2004 and is member of the Italian Engineering Board since 1992 (SM'02). Her teaching interests cover power plants based on renewable sources, cogeneration and trigeneration. Her current research interests include design, analysis and optimization of electrical machines, condition monitoring and diagnostics of electrical machines and drives, and systems based on renewable energies. She is co-author of two books and author of more than 100 published papers in technical journals and conference proceedings.

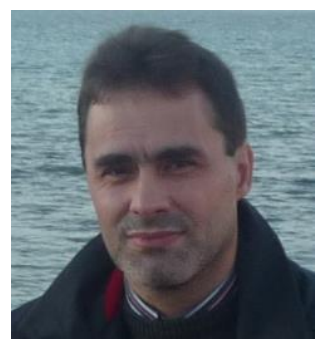

Adérito Neto Alcaso was born in Almeida, Portugal, in 1966. He received the Electrical Engineering. Diploma degree from the Technical University of Lisbon, Lisbon, Portugal, in 1990, and the M.S. degree in Systems and Automation and the Dr. Eng. degree in electrical engineering from the University of Coimbra, Coimbra, Portugal, in 1995 and 2005, respectively. Since 1991, he has been with the School of Technology and Management of the Polytechnic of Guarda, Guarda, Portugal, where he is currently an Assistant Professor in the Department of Engineering and Technology and the Director of the Electrical Machines Laboratory.

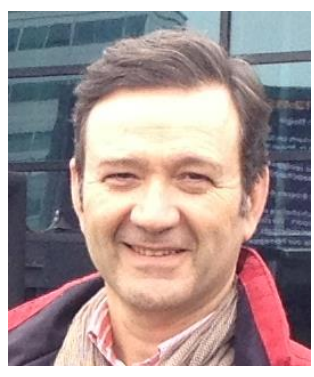

Carlos A. Figueiredo Ramos received the Mechanical Engineering diploma and the M.S. degree in Industrial Engineering, both from the University of Coimbra, Coimbra, Portugal. He is currently a Ph.D. student in Industrial Engineering and Management at the University of Beira Interior, Covilhã, Portugal. He is a professor at the Polytechnic of Guarda, Guarda, Portugal.

His research interests include renewable energies and energy systems.

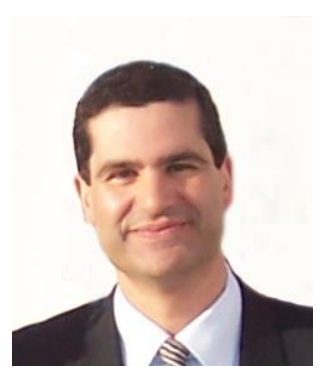

Antonio J. Marques Cardoso (StM'89, AM'95, SM'99) received the Dipl. Eng., Dr. Eng., and Habilitation degrees from the University of Coimbra, Coimbra, Portugal, in 1985, 1995 and 2008, respectively, all in Electrical Engineering. From 1985 until 2011 he was with the University of Coimbra, Coimbra, Portugal, where he was Director of the Electrical Machines Laboratory. Since 2011 he has been with the University of Beira Interior (UBI), Covilhã, Portugal, where he is Full Professor at the Department of Electromechanical Engineering and Director of CISE - Electromechatronic Systems Research Centre (http://cise.ubi.pt). He was ViceRector of UBI (2013-2014). His current research interests are in fault diagnosis and fault tolerance in electrical machines, 
power electronics and drives. He is the author of a book entitled Fault Diagnosis in Three-Phase Induction Motors (Coimbra, Portugal: Coimbra Editora, 1991), (in Portuguese) and of around 400 papers published in technical journals and conference proceedings. He serves as Guest Editor of the IEEE Transactions on Industry Applications Special Issue on Fault Diagnosis of Electric Machines, Power Electronics and Drives and Associate Editor for the IEEE Transactions on Industry Applications, IEEE Transactions on Industrial Electronics, IEEE Journal of Emerging and Selected Topics in Power Electronics, and also for the Springer International Journal of Systems Assurance Engineering and Management. 